\title{
Riqueza florística em uma área ciliar de Caatinga no Cariri Ocidental da Paraíba, Brasil
}

\section{Renally Cardoso Farias ${ }^{1}$, Alecksandra Vieira de Lacerda ${ }^{2 * *}$, Azenate Campos Gomes ${ }^{3}$, Francisca Maria Barbosa², Carina Seixas Maia Dornelas $^{2}$}

${ }^{1}$ Curso de Especialização em Etnobiologia. Universidade Estadual da Paraíba. Campina Grande-PB (CEP 58429-500).

${ }^{2}$ Centro de Desenvolvimento Sustentável do Semiárido. Universidade Federal de Campina Grande. Sumé-PB (CEP 58540-000).*E-mail alecvieira@yahoo.com.br.

${ }^{3}$ Programa de Pós-Graduação em Agronomia. Centro de Ciências Agrárias. Universidade Federal da Paraíba. Rodovia BR 079, km 12. Areia-PB (CEP 58397-000).

Resumo. Decorrente dos elevados níveis de fertilidade, as matas ciliares da Região Semiárida brasileira vêm sendo constantemente degradadas. Objetivou-se com este trabalho identificar a composição florística de um sistema ecológico ciliar conservado no Cariri paraibano. A pesquisa realizou-se no Riacho da Umburana, Município de Sumé, Cariri Ocidental da Paraíba. As coletas da vegetação arbustivo-arbórea foram realizadas quinzenalmente de forma assistemática. A classificação e identificação dos exemplares coletados foram realizadas através de consultas a especialistas e por meio de morfologia comparada, usando bibliografia especializada. As espécies foram organizadas por família, incluindo-se informações sobre o hábito. Foram registradas 57 espécies, distribuídas em 22 famílias e 42 gêneros. O componente predominante foi o arbóreo com 37 espécies. As Famílias Fabaceae, Euphorbiaceae, Anacardiaceae e Cactaceae se destacaram como as de maior riqueza, representando 49\% da amostra. Portanto, a frequência de espécies destas famílias na área, revela-se como subsídios para a elaboração de novos conceitos e estratégias para ocupar áreas do conhecimento lacunares, na compreensão de modelos de conservação e recuperação dos recursos vegetais em ecossistemas ciliares do semiárido.

Palavras-chave: Composição florística; Conservação ecossistêmica; Riachos intermitentes; Semiárido.

Abstract. Study of floristic richness in a riparian area of Caatinga
in western Cariri of Paraíba, Brazil. The riparian forests in the
semiarid region of Brazil have constantly been degraded because of
their high fertility. This study aimed to identify the floristic
composition of a riparian ecosystem preserved in the Cariri Region of
Paraíba State, Brazil. The research was performed in the Umburana
Stream, in the Municipality of Sumé, Western Cariri of Paraíba. The
collections of shrub-tree vegetation were carried out biweekly in an
unsystematic way. The collected specimens were classified and
identified by consulting experts and through comparative
morphology, using specialized literature. The species were classified
Recebido: 10/06/2017

Aceito: 27/06/2017

Publicado: 30/06/2017

Acesso Aberto Artigo completo

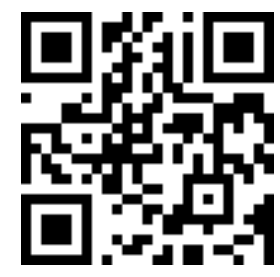

ORCIID

(1) 0000-0003-4112-3982 Renally Cardoso Farias

D 0000-0002-9703-3997

Alecksandra Vieira de Lacerda

(1) 0000-0001-6184-3114

Azenate Campos Gomes

D 0000-0002-6273-0979

Francisca Maria Barbosa

(D) 0000-0003-0602-7979

Carina Seixas Maia

Dornelas 
as their family, including information on their habit. A total of 57 species belonging to 22 families and 42 genera were recorded. The tree was the predominant component with 37 species. Fabaceae, Euphorbiaceae, Anacardiaceae, and Cactaceae stood out as the most abundant families, accounting for $49 \%$ of the sample. Therefore, the frequency of species of these families in the study area can be a support for the development of new concepts and strategies to fill the gaps in knowledge areas that are still incomplete and to understand the models of conservation and recovery of plant resources in riparian ecosystems in the semiarid region.

Keywords: Ecosystem conservation; Floristic composition; Intermittent streams; Semiarid.

\section{Introdução}

As matas ciliares veem sendo destacadas pela sua relevância para o equilíbrio dos ecossistemas ribeirinhos. Entretanto, apesar das evidências de sua importância e de sua proteção legal, a cobertura vegetal presente nas áreas ciliares vem sendo crescentemente degradada. Isso também é observado por vários autores que, de maneira geral, argumentam que em várias partes do Brasil a floresta ciliar encontra-se em diversos estágios de sucessão, dificilmente conservada, com exceção de alguns casos a exemplo de pequenos trechos de difícil acesso (Kageyama e Dias, 1982; Gorgônio, 1998; Mueller, 1998; Van den Berg e OliveiraFilho, 2000).

O levantamento da vegetação regional é fase de extrema importância em programas de restauração de áreas degradadas, pois, a partir das informações sobre os tipos de vegetação florestal, características da região, bem como, a sua estrutura fitossociológica e a classificação sucessional, é possível definir as estratégias de recuperação para cada situação identificada (Rodrigues e Gandolfi, 1996).

Nesse contexto, ressalta-se ainda a necessidade urgente de ações visando a conhecer, a proteger e a recuperar as áreas de vegetação ciliar na região Semiárida, as quais se encontram bastante degradadas e reduzidas a fragmentos cada vez menores e isolados. Associado a este cenário, tem-se reconhecido também os poucos estudos voltados para as matas ciliares em áreas de Caatinga (Lacerda et al., 2005; Lacerda e
Barbosa, 2006; Sousa e Rodal, 2010; Trovão et al., 2010; Silva et al., 2015). Atualmente ainda não se têm definido os seus aspectos ecológicos e pouco ou quase nada se conhece sobre os fatores que agem sobre o equilíbrio desses ambientes (Gomes et al., 2014; Moro et al., 2015).

Nas áreas ciliares da caatinga as plantas enfrentam condições específicas em relação ao solo, clima e formas de manejo sendo a definição desses fatores importante para ampliar os conhecimentos sobre os processos e as adaptações da vegetação ao meio em que se inserem. Assumindo os elementos dispostos, tem-se observado que os trabalhos nessas áreas viabilizam através de inventários e monitoramento das comunidades vegetais a identificação de processos e padrões os quais ajudarão a melhor adequar às estratégias ecológicas para restauração e conservação desses ambientes.

Levando em consideração a necessidade de subsídios para proposição de estratégias de restauração ecológica da fitodiversidade em área de Caatinga, objetivou-se com este trabalho identificar a composição florística de um sistema ecológico ciliar conservado no Cariri paraibano.

\section{Material e Métodos}

A pesquisa foi desenvolvida no Cariri paraibano, localizado este na franja ocidental do planalto da Borborema e mais particularmente na porção central, referente ao estado da Paraíba (Moreira, 1988). O trabalho de campo realizou-se no município 
de Sumé, situado na microrregião do Cariri Ocidental.

Inserida nos limites municipais de Sumé foi selecionada uma área de mata ciliar, a qual se definiu pelas seguintes características: remanescente com um significativo grau de conservação servindo os aspectos estruturais e funcionais que marcam este ecossistema de modelo para indicar, estruturar e adequar às propostas de restauração de ambientes perturbados.
Assim caracterizado, o Riacho da Umburana (7० 45' 15.3” S e $36^{\circ} 58^{\prime} 01.6^{\prime \prime}$ $\mathrm{W}$; altitude $571 \mathrm{~m}$ ) (Figura 1), tem sua nascente localizada no Sítio Boa Esperança, Município de Monteiro-PB e desemboca no Açude Jatobá, em Sumé. O trecho amostrado do riacho está definido dentro dos limites da Fazenda Nova. De acordo com a classificação de Köppen, o clima da região é do tipo climático BSh, seco (semiárido) (Cadier et al., 1983).

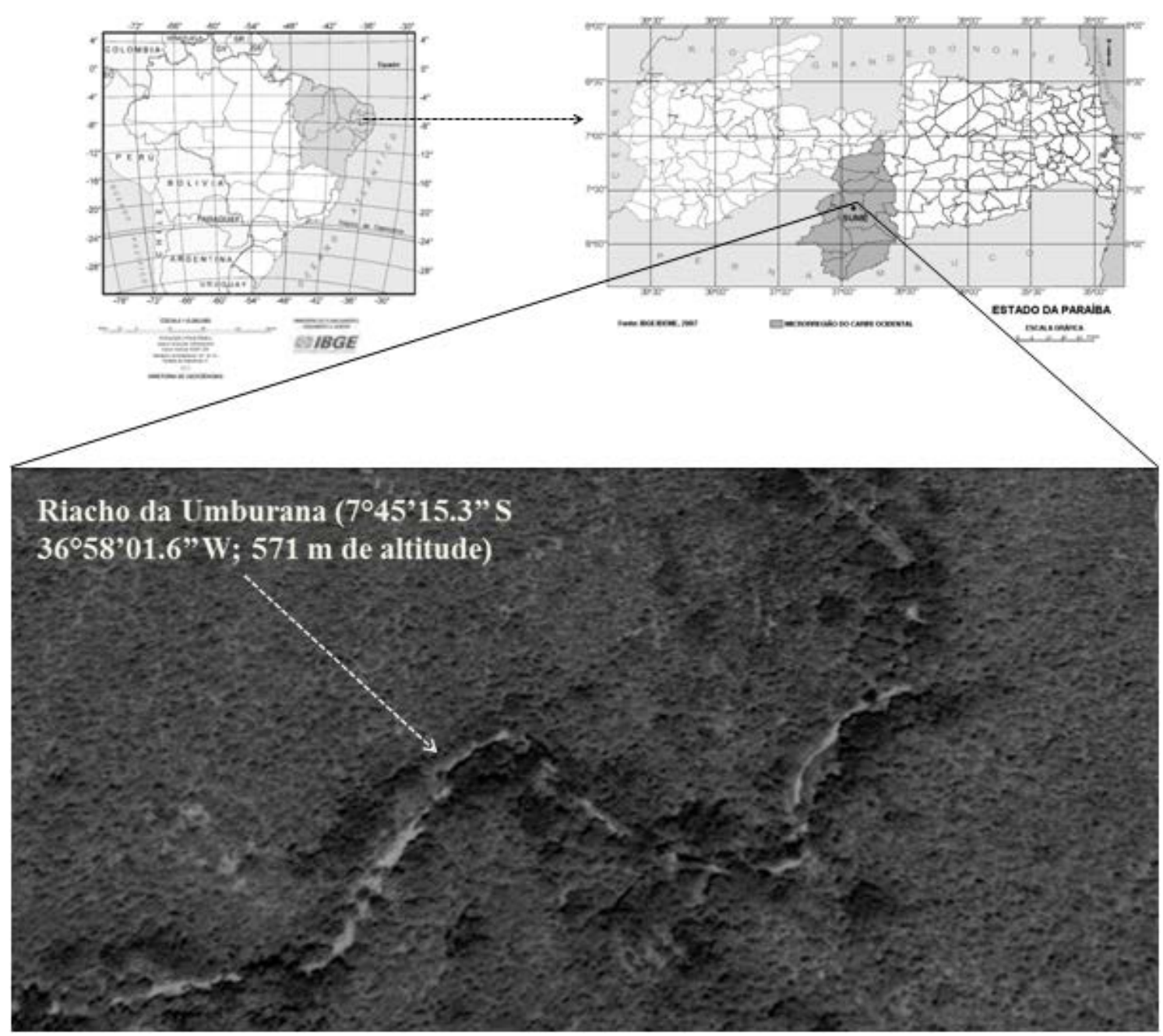

Figura 1. Localização do Riacho da Umburana no Município de Sumé, Semiárido da Paraíba, Brasil.

A estação chuvosa se concentra em três meses do ano, com precipitação anual média de $590 \mathrm{~mm}$. A temperatura média anual é de $24^{\circ} \mathrm{C}$, a insolação anual média é de 2800 horas e a evaporação anual média no tanque classe A é de $2900 \mathrm{~mm}$. O solo predominante é o Luvissolo, representativo da zona semiárida, com permeabilidade lenta. Definidos como bastantes jovens, os solos apresentam profundidade em torno de 
$50 \mathrm{~cm}$ a $1 \mathrm{~m}$, e em muitos locais ocorre afloramento de rocha. O relevo é pouco ondulado a ondulado (Srinivasan et al., 2003).

Relacionado particularmente à vegetação ciliar tem-se que esta é predominantemente arbórea, com ocorrência de espécies arbustivas bastante ramificadas a partir da base e presença de estrato herbáceo que se mostra abundante no período chuvoso.

As atividades foram apoiadas na análise de cartas e mapas da vegetação e excursões exploratórias realizadas inicialmente em vários pontos no Município de Sumé. Assumindo esse primeiro estudo e obedecendo como critério de seleção amostrar ambientes mais conservados, foi selecionada para o levantamento florístico uma área ciliar ao longo de um curso d'água intermitente. A escolha deste tipo de levantamento se apoia na base teórica que o define como aquele que permite efetuar comparações relativamente simples e eficientes entre áreas (Van den Berg e Oliveira-Filho, 2000).

As coletas da vegetação arbustivoarbórea foram realizadas quinzenalmente e processadas de forma assistemática. Os exemplares encontram-se depositados na Coleção de Plantas do Laboratório de Ecologia e Botânica do Centro de
Desenvolvimento Sustentável do Semiárido (CDSA/UFCG) e a coleta foi autorizada pelo SISBIO (79457917). A identificação e/ou confirmação dos exemplares coletados foram realizadas através de consultas a especialistas e por meio de morfologia comparada, usando bibliografia especializada. As espécies foram organizadas por família no sistema APG III (2009), incluindo-se informação sobre o hábito. A grafia dos nomes dos autores dos táxons e suas respectivas abreviações foram verificadas através de Brummitt e Powell (1992). Os nomes populares estão de acordo com o conhecimento local.

\section{Resultados e discussão}

$\mathrm{Na}$ área ciliar do Riacho da Umburana foram registradas 57 espécies, das quais, 48 foram identificadas no nível de espécie, três no genérico e seis permaneceram indeterminadas. As espécies identificadas encontraram-se distribuídas em 22 famílias e 42 gêneros. O componente predominante foi o arbóreo com 37 espécies. Desta sinúsia, três espécies permaneceram indeterminadas e as restantes ficaram distribuídas em 15 famílias (Tabela 1).

Tabela 1. Lista das famílias e espécies registradas no levantamento florístico realizado na área ciliar do Riacho da Umburana, Sumé-PB. Hab. = Hábito.

\begin{tabular}{lll}
\hline Taxon & Nome popular & Hab. \\
\hline 1. ANACARDIACEAE & & \\
1. Myracrodruon urundeuva Allemão & Aroeira & Arbóreo \\
2. Schinopsis brasiliensis Engl. & Baraúna & Arbóreo \\
3. Spondias tuberosa Arruda & Umbuzeiro & Arbóreo \\
2. ANNONACEAE & & \\
4. Rollinia leptopetala (R. E. Fries) Safford & Pinha-brava & Arbusto \\
3. APOCYNACEAE & & \\
5. Aspidosperma pyrifolium Mart. & Pereiro & Arbóreo \\
4. BIGNONIACEAE & & \\
6. Tabebuia aurea (Silva Manso) Benth. \& Hook. f. ex Craibeira & Arbóreo \\
S. Moore & & \\
5. BRASSICACEAE & & \\
7. Capparis flexuosa (L.) L. & Feijão-bravo & Arbóreo \\
8. Capparis jacobinae Moric. ex Eichler & Icó & Arbóreo \\
\hline
\end{tabular}


Tabela 1. Continuação.

\begin{tabular}{l} 
Taxa \\
\hline 6. BORAGINACEAE \\
9. Cordia leucocephala Moric. \\
10. Tournefortia rubicunda Salzm. ex A. DC. \\
7. BURSERACEAE \\
11. Commiphora leptophloeos (Mart.) J. B. Gillett. \\
8. CACTACEAE \\
12. Cereus jamacaru DC. \\
13. Pilosocereus gounellei (Weber) Byles \& Row \\
14. Pilosocereus pachycladus subsp. Pernambuce \\
(Ritter) Zappi \\
9. CELASTRACEAE \\
15. Maytenus rigida Mart. \\
10. COMBRETACEAE \\
16. Combretum pisonioides Taub. \\
11. ERYTHROXYLACEAE \\
17. Erythroxylum revolutum Mart. \\
12. EUPHORBIACEAE \\
18. Croton adenocalyx Baill. \\
19. Croton blanchetianus Baill. \\
20. Croton echioides Baill. \\
21. Ditaxis malpighiacea (Ule) Pax \& K. Hoffm. \\
22. Jatropha mollissima (Pohl) Baill. \\
23. Manihot catingae Ule \\
24. Sapium glandulosum (L.) Morong \\
25. Sebastiania macrocarpa Müll. Arg.
\end{tabular}

13. FABACEAE

13.1 FABACEAE subfam. CAESALPINIOIDEAE

26. Bauhinia cheilantha (Bong.) Steud.

27. Libidibia ferrea (Mart. Ex Tul.) L. P. Queiroz

28. Poincianella pyramidalis (Tul.) L. P. Queiroz

29. Senna martiana (Benth.) Irwin \& Barneby

30. Senna spectabilis (DC.) Irwin \& Barneby

13.2 FABACEAE subfam. FABOIDEAE

31. Lonchocarpus cf. obtusus Benth.

32. Poecilanthe ulei (Harms) Arroyo \& Rudd

13.3 FABACEAE subfam. MIMOSOIDEAE

33. Anadenanthera colubrina (Vell.) Brenan

34. Chloroleucon foliolosum (Benth.) G. P. Lewis

35. Mimosa ophthalmocentra Mart. ex Benth.

36. Mimosa tenuiflora (Willd.) Poir.

37. Mimosa sp.

38. Piptadenia stipulacea (Benth.) Ducke

39. Parapiptadenia SP

14. MALVACEAE

40. Helicteres brevispira A. St.-Hil.

15. NYCTAGINACEAE

41. Guapira laxa (Netto) Furlan

16. RHAMNACEAE

42. Rhamnidium molle Reissek

43. Ziziphus cotinifolia Reissek

44. Ziziphus joazeiro Mart.

17. RUBIACEAE

45. Alibertia SP

46. Guettarda angelica Mart. ex Müll. Arg.
Hab.

Nome popular

Arbusto

Moleque-duro

Arbusto

Maria-preta

Arbóreo

Amburana de cambão

Arbóreo

Arbusto

Arbóreo

Xique-xique, Alastrado

Facheiro

Bonome

Arbóreo

Canela-de-veado

Arbóreo

Arbóreo

Velame-brabo

Arbusto

Marmeleiro

Caatinga-branca

Arbusto

Arbusto

Arbusto

Arbusto

Arbóreo

Arbóreo

Arbóreo

Burra-leiteira

Pau-leite

Arbusto

Mororó

Arbóreo

Arbóreo

Arbusto

Canafístula-brava

Arbóreo

Rabo de cavalo

Arbóreo

Chorão

Arbóreo

Angico

Arbóreo

Jurema-açu

Jurema-de-imbira

Jurema-preta

Arbóreo

Arbóreo

Arbóreo

Arbóreo

Jurema-branca

Angico-manjola

Arbóreo

Arbóreo

Guaxumbu

Arbusto

João-mole, Piranha

Arbóreo

Sassafrás

Arbóreo

Juazeiro

Arbóreo

Arbóreo

Arbusto

Arbusto 
Tabela 1. Continuação.

\begin{tabular}{lll}
\hline Taxa & Nome popular & Hab. \\
\hline 18. SALICACEAE & & Arbusto \\
47. Prockia crucis P. Browne ex L. & & Arbóreo \\
9. SAPINDACEAE & Batinga & \\
48. Allophylus quercifolius Radlk. & & Arbóreo \\
20. SAPOTACEAE & & \\
49. Sideroxylon obtusifolium (Roemer \& Schultes) T. Quixabeira & Arbusto \\
D. Penn. & & \\
21. SOLANACEAE & Alecrim & Arbusto \\
50. Capsicum parvifolium Sendtn. & & \\
22. VERBENACEAE & & Arbóreo \\
51. Lippia gracilis Schauer & & Arbusto \\
INDETERMINADAS & & Arbóreo \\
52. Indeterminada 1 & & Arbóreo \\
53. Indeterminada 2 & & Arbusto \\
54. Indeterminada 3 & & Arbusto \\
55. Indeterminada 4 & & \\
56. Indeterminada 5 & & \\
57. Indeterminada 6 & & \\
\hline
\end{tabular}

O total de espécies arbóreas e arbustivas listado (57), para a mata ciliar é considerado expressivo ao se comparar com os números apresentados por Rodrigues e Nave (2004) quando analisaram 43 trabalhos realizados em florestas ciliares do Brasil extra-amazônico, em condições de clima e de altitude muito variáveis. Segundo esses autores o número de espécies arbustivo-arbóreas amostrado variou entre 23 e 247 nos trabalhos apresentados.

$\mathrm{Na}$ análise de seis trabalhos de composição florística de matas ciliares realizados na Caatinga, tem-se que 0 número de espécies varia de 17 a 61 e as famílias de 7 a 54 (Van den berg e OliveiraFilho, 2000; Santos e Vieira, 2006; Lima, 2009; Oliveira et al., 2009; Trovão et al., 2010; Bessa e Medeiros, 2011). De modo particular, no Cariri paraibano, Lacerda et al. (2010), ao estudar três áreas de mata ciliar registrou um número de espécies que variou entre 56 e 68 . Vale salientar que a área representada por 68 espécies está localizada em uma unidade de conservação considerada a mais preservada da região, a Reserva Particular do Patrimônio Natural (RPPN) Fazenda Almas, o que mostra a semelhança em termos de riqueza florística do componente arbóreo e arbustivo com a área estudada.

Na RPPN Fazenda Almas, no Cariri Paraibano, Barbosa et al. (2007) registrou em área de terra firme 67 espécies arbóreoarbustivo. Em uma área com 30 anos de conservação no Município de Monteiro, também no Estado da Paraíba, Pereira Júnior et al. (2012) registrou 37 espécie. Já em uma área de vegetação natural em Senhor do Bom Fim, na Bahia, Ramalho et al. (2009) encontrou 57 espécies, o mesmo valor encontrado neste estudo.

As famílias com maior número de espécies e gêneros no estrato arbustivoarbóreo foram Fabaceae com 14 espécies e 10 gêneros, Euphorbiaceae representada com oito espécies e seis gêneros, Anacardiaceae com três espécies e três gêneros e Cactaceae três espécies e dois gêneros (Figura 2). Juntas, essas Famílias representam 49\% da amostra estudada. Além disso, tem-se que as duas primeiras famílias estão relacionadas entre as oito famílias mais ricas registradas em trabalhos realizados em florestas ciliares do Brasil extra-amazônico (Rodrigues e Nave, 2004).

Conforme Forzza et al. (2010), Fabaceae e Euphobiaceae estão entre as dez famílias mais representativas nos diferentes 
domínios fitogeográficos brasileiros, as quais ocupam a primeira e a nona posição, respectivamente. Segundo Rizzini (1987), na Caatinga encontra-se o grupo do maior número de espécies de cactáceas do Brasil.
De acordo com Sarmiento (1975), Fabaceae Euphorbiaceae e Cactaceae também ocupam papel de destaque em outras formações xerófilas na América do Sul.

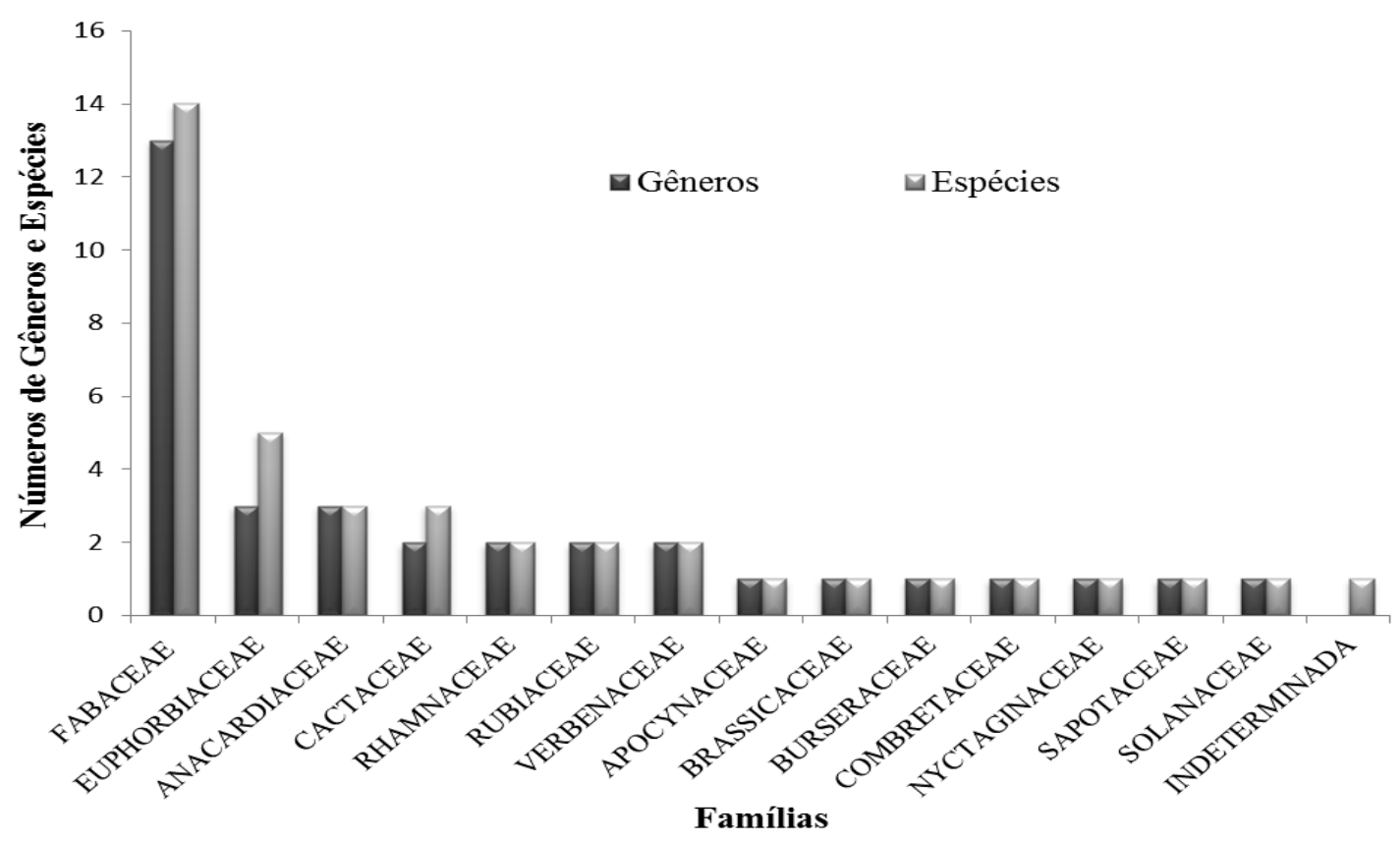

Figura 2. Distribuição do número total de espécies e de gêneros amostrado por famílias para área ciliar do Riacho da Umburana, Sumé, Paraíba, Brasil.

Das três espécies registradas da Família Anacardiaceae, M. urundeuva e S. brasiliensis são consideradas como espécies ameaçadas de extinção devido ao seu elevado potencial madeireiro associado aos seus históricos de exploração predatória intensiva (Luz et al., 2013; Gomes et al., 2016). Ainda de acordo com a lista de espécies ameaçadas da flora brasileira (Martinelli e Moraes, 2013) essas espécies são as únicas citadas para o Bioma Caatinga. Entretanto, deve-se ressaltar que estudos tem apontado baixos valores de densidade de indivíduos em algumas espécies em vários ecossistemas deste Bioma (Santos e Vieira, 2006; Lima, 2009; Oliveira et al., 2009; Trovão et al., 2010; Bessa e Medeiros, 2011, Pereira Junior et al., 2012), implicando assim em níveis acentuados de simplificação biológica nos sistema dessa região.

Relacionado aos gêneros, a maior parte (35) possui apenas uma espécie, ficando sete gêneros com mais de uma espécie. Estes dados apontam para uma tendência na vegetação estudada, a exemplo do que ocorre na Caatinga, em apresentar baixa diversidade dentro dos táxons. Especificamente para a Caatinga, este fato é também destacado nos trabalhos de Ferreira (1988), Rodal (1992), Araújo et al. (1995), Lacerda et al. (2010).

Estudos florísticos e fitossociológicos teem mostrado a ocorrência de determinadas espécies com maior frequência em determinadas condições de microhabitats. Neste aspecto 
tem-se que as áreas próximas aos cursos d'águas geralmente são ocupadas em maior número por espécies como $Z$. joazeiro, S. obtusifolium, T. aurea, S. brasiliensis (Lacerda e Barbosa, 2005; Ferraz et al., 2006; Rodal et al., 2008). Já autores como Ferraz (1998) e Lacerda et al. (2010) destacam que para áreas de mata ciliar espécies de Rubiaceae são bastante frequentes devido à umidade presente nestes ambientes.

No Rio Cariranha, no norte de Minas Gerais, Santos e Vieira (2005) observaram que Anacardiaceae e Euphorbiaceae estão dentre as famílias de maior riqueza. Para os autores, Sousa et al. (2009) e Nogueira et al. (2012), o conhecimento da riqueza florística de áreas com expressivos valores para 0 embasamento de programas de recuperação de áreas degradadas tem sido uma pratica de resultados exitosos.

\section{Conclusão}

Os resultados gerados neste trabalho mostram a expressiva riqueza da área estudada, tendo em vista que os valores para este parâmetro são semelhantes a resultados encontrados para a Reserva Particular do Patrimônio Natural (RPPN) Fazenda Almas, localizada em São João do Cariri-PB, considerada como uma das mais conservadas do semiárido paraibano. As Famílias Fabaceae, Euphorbiaceae, Anacardiaceae e Cactaceae destacaram-se como as de maior riqueza, representando $49 \%$ da amostra. Portanto a frequência de espécies destas famílias na área revelam-se como subsídios para a elaboração de novos conceitos e estratégias para ocupar áreas do conhecimento que se constituem em lacunas na compreensão de modelos de conservação e restauração dos ecossistemas ciliares da região e dos seus respectivos recursos vegetais.

\section{Agradecimentos}

Ao $\mathrm{CNPq}$ pelo financiamento da pesquisa, a família Mayer, proprietários da Fazenda Nova, e aos integrantes do Laboratório de Ecologia e Botânica.

\section{Declaração de conflito de interesses}

Os autores declaram não haver conflitos de interesses.

\section{Referências}

APG III. An update of the Angiosperm Phylogeny Group classification for the orders and families of flowering plants. Botanical Journal of the Linnean Society, v. 161, n. 105121, 2009.

Araújo, E. L.; Sampaio, E. V. S. B.; Rodal, M. J. N. Composição florística e fitossociológica de três áreas de Caatinga. Revista Brasileira de Biologia, v. 55, p. 595-607, 1995.

Brummitt, R. F.; Powell, C. E. Authors of plant names. London: Royal Botanic Gardens/Kew, 1992.

Barbosa, M. R. V.; Lima, I B.; Lima， J. R.; Cunha, J. P.; Agra, M. F.; Thomas, W.W. Vegetação e flora no cariri paraibano. Oecologia Brasiliensis, v. 11, p. 313-322, 2007.

Bessa, M. A. P.; Medeiros, J. F. Levantamento florístico e fitossociológico em fragmentos de caatinga no Município de Taboleiro GrandeRN. GEO Terras, v. 1, p. 69-83, 2011.

Cadier, E.; Freitas, B. J.; Leprun, J. C. Bacia Experimental de Sumé: instalação e primeiros resultados. Recife: SUDENE, 1983. (Série Hidrológica, 16).

Ferraz, E. M. N.; Rodal, M. J. N.; Sampaio, E. V. S. B.; Pereira, R. C. A. Composição florística em trechos de caatinga e brejo de altitude na Região do Vale do Pajeú, Pernambuco. Revista Brasileira de Botânica, v. 21, p. 7-15, 1998.

Ferraz, J. S. F.; Albuquerque, U. P.; Meunier, I. M. J. Valor de uso e estrutura da vegetação lenhosa às margens do Riacho do Navio, Floresta, Pernambuco. Acta Botanica Brasilica, v. 20, p. 1-10, 2006.

Ferreira, R. L. C. Análise estrutural da vegetação da Estação Florestal de experimentação de Açu-RN, como subsídio básico para o manejo florestal. Viçosa: Universidade Federal de Viçosa, 1988. (Dissertação de mestrado).

Forzza, R. G.; Baumgratz, J. F.; Costa, A.; Hopkins, M.; Leitman, P. M.; Lohmann, L. G.; Martinelli, G.; Morin, M. P.; Coelho, M. A. N.; Peixoto, A. L.; Pirani, J. R.; Queiroz, L. P.; Stehmann, R.; Walter, B. M. T.; Zappi, D. As angiospermas do Brasil. In: Forzza, R. C.; Baumgratz, J. F. A.; Bicudo, C. E. M.; Carvalho Jr., A. A.; Costa, A.; Costa, D. P.; Hopkins, M.; Leitman, P. M.; Lohmann, L. G.; Maia, L. C.; 
Martinelli, G.; Menezes, M.; Morim, M. P.; Coelho, M. A. N.; Peixoto, A. L.; Pirani, J. R.; Prado, J.; Queiroz, L. P.; Souza, V. C.; Stehmann, J. R.; Sylvestre, L. S.; Walter, B. M. T.; Zappi, D. (Eds.). Catálogo de plantas e fungos do Brasil. Rio de Janeiro: Instituto de Pesquisas Jardim Botânico, 2010. v. 1. p. 78-88. Disponível em: <http://reflora.jbrj.gov.br/ downloads/vol1.pdf>. Acesso em: 25 fev. 2017.

Gomes, D. S.; Ribeiro, J. E. S.; Lucena, R. F. P. Uso e disponibilidade local da aroeira Myracrodruon urundeuva (Allemão) Engl. (Magnoliopsida: Anacardiaceae) em uma comunidade rural da Depressão Sertaneja, São José de Piranhas, Estado da Paraíba, Brasil. Revista Brasileira de Gestão Ambiental e Sustentabilidade, v. 3, n. 6, p. 265-276, 2016. https://dx.doi.org/10.21438/rbgas.030602

Gomes, F. S.; Guedes, M. L.; Valadão, R. M.; Prates, A. R.; Costa, M. A. Florística e estrutura de um trecho de mata ciliar do Rio Carinhanha, Feira da Mata, Bahia, Brasil. Biotemas, v. 27, p. 41-55, 2014.

Gorgônio, A. S. Estudo ambiental de alterações antrópicas nas matas de galeria da Bacia Hidrográfica do Ribeirão Taboca. Brasília: Instituto Brasileiro do Meio Ambiente e dos Recursos Naturais Renováveis, 1998.

IBGE - Instituto Brasileiro de Geografia e Estatística. Mapa da Região Nordeste. 2013. Disponível em: <ftp://geoftp.ibge.gov.br/ mapas_tematicos/fisico/regionais/nordeste_fisic o.pdf $>$. Acesso em: 19 out. 2015.

Kageyama, P. Y.; Dias, I. S. Aplicação da genética em espécies florestais nativas. Silvicultura, v. 16, p. 728-791, 1982.

Lacerda, A. V.; Barbosa, F. M. Matas ciliares no Domínio das Caatingas. João Pessoa: Editora Universitária/UFPB, 2006.

Lacerda, A. V.; Barbosa, F. M.; Soares, J. J.; Barbosa, M. R. V. Flora arbustiva-arbórea de três áreas ribeirinhas no semiárido paraibano, Brasil. Biota Neotropica, v. 10, p. 275-284, 2010.

Leal, I. R.; Tabarelli, M.; Silva, J. M. C. Ecologia e conservação da caatinga. Recife: Editora Universitária da UFPE, 2003.

Lima, J. R. Diagnóstico do solo, água e vegetação em um trecho do Rio Chafariz Santa Luzia (PB). Patos: Patos: Universidade Federal de Campina Grande, 2009. (Dissertação de mestrado).

Luz, C. L. S.; Pirani, J. R.; Valente, A. S. M.; Fernandez, E. P.; Penedo, T. S. A.; Borges, R. A. X. Anacardiaceae. In: Martinelli, G.;
Moraes, M. A. Livro vermelho da flora do Brasil. Rio de Janeiro: Instituto de Pesquisas Jardim Botânico do Rio de Janeiro, 2013. p. 140-141.

Martinelli, G.; Moraes, M. A. (Org.). Livro vermelho da flora do Brasil. 1. ed. Rio de Janeiro: Andrea Jakobsson, Instituto de Pesquisas Jardim Botânico do Rio de Janeiro, 2013. Disponível em: $<$ http://cncflora.jbrj.gov.br/arquivos/arquivos/pd fs/LivroVermelho.pdf>. Acesso em: 25 fev. 2017.

Moreira, E. R. F. (Org.). Mesorregiões e Microrregiões da Paraíba: delimitação e caracterização. João Pessoa: GAPLAN, 1988.

Moro, M. F.; Macedo, M. B.; Moura-Fé, M. M.; Farias, A. S. Vegetação, unidades fitoecológicas e diversidade paisagística do Estado do Ceará. Rodriguésia, v. 66, n. 3, p. A1-A10, 2015. https://dx.doi.org/10.1590/21757860201566305

Mueller, C. C. Gestão de matas ciliares. In: Lopes, I. V. (Org.). Gestão ambiental no Brasil: experiência e sucesso. 2. ed. Rio de Janeiro: Editora Fundação Getúlio Vargas, 1998. p. 185-214.

Nogueira, N. O.; Onair, M. O.; Martins, C. A. S.; Bernardes, C. O. Utilização de leguminosas para recuperação de áreas degradadas. Enciclopédia Biosfera, v. 8, p. 2121-2131, 2012.

Oliveira, E. B.; Marangon, L. C.; Feliciano, A. L. P.; Ferreira, R. L. C.; Rêgo, P. L. Estrutura fitossociológica de um fragmento de mata ciliar, Rio Capibaribe Mirim, Aliança, Pernambuco. Revista Brasileira de Ciências Agrárias, v. 4, p. 167-172, 2009.

Pereira Júnior, L. R.; Andrade, A. P.; Araújo, K. D. Composição florística e fitossociológica de um fragmento de Caatinga em Monteiro, PB. Revista Holos, v. 6, p. 73-87, 2012.

Ramalho, C. I.; Andrade, A. P.; Félix, L. P.; Lacerda, A. V.; Maracajá, P. B. Flora arbóreoarbustiva em áreas de Caatinga no Semiárido Baiano, Brasil. Revista Caatinga, v. 22, p. 182-190, 2009.

Rizzini, C. Cactáceas: os segredos da sobrevivência. Ciência Hoje, v. 30, p. 30-39, 1987.

Rodal, M. J. N. Fitossociologia da vegetação arbustivo-arbórea em quatro áreas de Caatinga em Pernambuco. Campinas: Universidade Estadual de Campinas, 1992. (Tese de doutorado). 
Rodrigues, R. R.; Gandolfi, S. Recomposição de florestas nativas: princípios gerais e subsídios para uma definição metodológica. Revista Brasileira de Horticultura Ornamental, v. 2, p. 4-15, 1996.

Rodrigues, R. R.; Nave, A. G. Heterogeneidade florística das matas ciliares. In: Rodrigues, R. R.; Leitão Filho, H. F. (Eds.). Matas ciliares: conservação e recuperação. São Paulo: EDUSP/FAPESP, 2004. p. 45-72.

Santos, R. M.; Vieira, F. A. Estrutura e florística de um trecho de mata ciliar do Rio Carinhanha no extremo norte de Minas Gerais, Brasil. Revista Científica Eletrônica de Engenharia Florestal, v. 1, p. 1-13, 2005.

Santos, R. M.; Vieira, F. A. Florística e estrutura da comunidade arbórea de fragmentos de matas ciliares dos Rios São Francisco, Cochá e Carinhanha, norte de Minas Gerais, Brasil. Revista Científica Eletrônica de Engenharia Florestal, v. 4, p. 1-21, 2006.

Sarmiento, G. The dry plant formations of South America and their forest connections. Journal of Biogeography, v. 2, p. 233-251, 1975.

Silva, F. G.; Silva, R. H.; Araújo, R. M., Lucena, M. D. F. A.; Sousa, J. M. Levantamento florístico de um trecho de mata ciliar na Mesorregião do Sertão Paraibano. Revista Brasileira de Biociências, v. 13, p. 250-258, 2015.
Silva, L. S.; Alves, A. R.; Nunes, A. K. A.; Sousa, M. W.; Rocha, M. A. Florística, estrutura e sucessão ecológica de um remanescente de mata ciliar na Bacia do Rio Gurguéia-PI. Nativa, v. 3, p. 156-164, 2015.

Souza, A. M.; Carboni, M.; Vieira, A. S. Riqueza em espécies arbóreas utilizadas no Projeto Mata Ciliar na Microbacia do Santo Antonio no Município de Jaú/SP. Jaú: Instituto Pró-Terra, 2009.

Srinivasan, V. S.; Santos, C. A. G.; Galvão, C. O. Erosão hídrica do solo no semiárido brasileiro: a experiência na Bacia Experimental de Sumé. Revista Brasileira de Recursos Hídricos, v. 8, p. 57-73, 2003.

Trovão, D. M. B. M.; Freire, A. M.; Melo, I. J. M. M. Florística e fitossociologia do componente lenhoso da mata ciliar do Riacho de Bodocongó, semiárido paraibano. Revista Caatinga, v. 23, p. 78-86, 2010.

Van den Berg, E.; Oliveira-Filho, A. T. Composição florística e estrutura fitossociológica de uma floresta ripária em Itutinga, MG, e comparação com outras áreas. Revista Brasileira de Botânica, v. 23, p. 231-253, 2000.

Informação da Licença: Este é um artigo Open Access distribuído sob os termos da Licença Creative Commons Attribution, que permite uso irrestrito, distribuição e reprodução em qualquer meio, desde que a obra original seja devidamente citada. 